\title{
Article \\ Skin Antiaging Effects of the Fermented Outer Layers of Leaf Skin of Aloe barbadensis Miller Associated with the Enhancement of Mitochondrial Activities of $U V_{b}$-Irradiated Human Skin Fibroblasts
}

\author{
Hyeonwoo Lee ${ }^{1}$, Woonyong Choi ${ }^{2}$ D, Hyangseon Ro $^{3}$, Gyurae Kim $^{1}$ and Hyeonyong Lee ${ }^{4, *(D)}$ \\ 1 R\&DB Center, Beauty Science, Ltd., 220 Gasangil, Sejong 30003, Korea; hellohwlee@gmail.com (H.L.); \\ kgr1385@naver.com (G.K.) \\ 2 Jeju Marine Research Center, Korea Institute of Ocean Science and Technology (KIOST), Jeju 63349, Korea; \\ cwy@kiost.ac.kr \\ 3 R\&D Center, NOWCOS, Ltd., A-1004 BYC Highcity, Gasandigital 1, Seoul 08506, Korea; rohs@nowcos.co.kr \\ 4 Department of Medical Biomaterials Engineering, College of Biomedical Science, \\ Kangwon National University, Kangwon University Road 1, Chuncheon 24341, Korea \\ * Correspondence: hyeonl@kangwon.ac.kr; Tel.: +82-33-250-6560
}

check for updates

Citation: Lee, H.; Choi, W.; Ro, H.; Kim, G.; Lee, H. Skin Antiaging Effects of the Fermented Outer Layers of Leaf Skin of Aloe barbadensis Miller Associated with the Enhancement of Mitochondrial Activities of

$\mathrm{UV}_{\mathrm{b}}$-Irradiated Human Skin Fibroblasts. Appl. Sci. 2021, 11, 5660. https://doi.org/10.3390/app11125660

Academic Editor: Adriana Basile

Received: 1 May 2021

Accepted: 15 June 2021

Published: 18 June 2021

Publisher's Note: MDPI stays neutral with regard to jurisdictional claims in published maps and institutional affiliations.

Copyright: (c) 2021 by the authors. Licensee MDPI, Basel, Switzerland. This article is an open access article distributed under the terms and conditions of the Creative Commons Attribution (CC BY) license (https:/ / creativecommons.org/licenses/by/ $4.0 /)$.
Abstract: This study is the first to show that increased mitochondrial activities improved the antiaging effects of Aloe vera leaf skin fermented by Lactobacillus plantarum on $\mathrm{UV}_{\mathrm{b}}$-irradiated skin fibroblasts. The fermented extract (AF) increased the activities of mitochondrial reductase and the complex II and significantly reduced reactive oxygen species (ROS) production, even under $\mathrm{UV}_{\mathrm{b}}$ stress conditions, and also increased DPPH free radical scavenging activities compared with the hot water extract of outer layers of aloe leaf (AW) and quercetin itself. AF exerted a synergistic effect with quercetin and bioactive substances derived from the fermentation process. Moreover, mitochondrial activation of $\mathrm{UV}_{\mathrm{b}}$-irradiated human skin fibroblasts by $0.3 \%(w / v)$ of the AF plays important roles in increasing collagen production up to $125 \pm 5.45 \%$ and decreasing MMP-1 secretion down to $69.41 \pm 2.63 \%$ of the control levels. The AF enhanced the upregulation of collagen gene expression, and this change was also greater than those induced by the AW and quercetin. Therefore, this study concludes that fermentation of the skin of aloe leaves increases the activation of mitochondria and inhibits the photo-aging of $\mathrm{UV}_{\mathrm{b}}$-irradiated skin fibroblasts.

Keywords: leaf skin of Aloe vera; mitochondrial activities; skin antiaging; lactic acid fermentation

\section{Introduction}

Skin aging has been explained as intrinsic or extrinsic aging that is often induced by photo-aging. Compared to intrinsic aging due to the senescence of the human body, photo-aging is caused by chronic exposure to environmental factors, mainly ultraviolet (UV) radiation. It eventually results in skin fragility, wrinkling, roughness, dryness, and hyperpigmentation [1-3]. In general, skin aging is considered most closely related to photo-aging [2]. Among the three types of solar $U V$ rays, $U_{a}, U V_{b}$, and $U_{c}, U V_{b}$ radiation in the wavelength range of 280 to $315 \mathrm{~nm}$ is considered most damaging to the skin because it results in sunburns, erythema, acute inflammation, and skin cancers, which are often caused by photo-aging of the skin [4,5]. Exposure of human skin to UV radiation increases the synthesis of various matrix metalloproteinases (MMPs), which are implicated in photo-aging and the destruction of the extracellular matrix (ECM) due to the loss of collagen [6]. Oxidative stress due to exposure to $U_{\mathrm{b}}$ radiation substantially increases the levels of reactive oxygen species (ROS), which generate oxidative photo-lesions in DNA, proteins, and lipids in the skin [4,7]. UV-induced oxidative damage also directly induces mitochondrial ROS production, since mitochondria are the primary organelle affected by 
UV-induced skin aging. Several results support the hypothesis of the close association between mitochondria and skin health either via an increase in ATP production or free radical scavenging activity [8,9]. Therefore, an increase in mitochondrial activities and a decrease in ROS levels would be a worthwhile approach that has never been used to prevent skin aging as an extensive review on the relationship between flavonoids and mitochondrial activation for cytoprotection [10].

This goal could be achieved by administering aloe, a medicinal plant that has mainly been used to treat skin disorders for thousands of years. Among the many aloe species, the gel of Aloe barbadensis Miller, commonly called Aloe vera, obtained by peeling the skin off the leaves and has been most widely used as a food supplement and cosmetic ingredient due to its various biological effects, such as the treatment of burns and anti-inflammatory and antibacterial properties [11-13]. However, the remaining parts of Aloe vera have not been utilized much due to their very bitter tastes and hardness, although they contain more biologically active substances, such as aloins, aloe-amodin, and polyphenols [12,13]. Moreover, more than $97 \%$ of the gel is composed of water [14], and the remaining constituents mainly include polysaccharides such as acemannan and mannose $[15,16]$. In addition, anthraquinones, which are considered to possess strong anti-inflammatory, antiprotozoal, and antioxidant activities, only exist on the leaf [17].

Therefore, it is necessary to develop a technique for processing the relatively hard parts of Aloe vera while maintaining its good efficacies to utilize this leaf skin efficiently. Lactic acid fermentation could primarily be considered since this process is operated under low temperature and mild extraction conditions, which would not degrade the bioactive substances in leaf skin $[18,19]$. The fermentation process has also been shown to improve the elution yields of active components from natural resources, especially the hard structures of the plants, along with the bioconversion of its metabolites, which increase its efficacies by promoting synergistic effects with various components in the extracts $[19,20]$. Lactobacillus family members have generally been employed for this purpose because the extracts obtained from the fermentation of plant resources with Lactobacillus species exert many useful effects on treating skin disorders through metabolites obtained during fermentation processes [21-23]. Therefore, in this study, the fermentation of the skin of Aloe vera leaves by L. plantarum was performed to show the possibility of preventing skin aging through the activation of mitochondria and increased its antioxidant activities.

\section{Materials and Methods}

\subsection{Preparation of the Samples}

For the control of the extracts, first, the outer layers of aloe leaf were obtained by peeling off the leaf of the whole areal parts, only to remove the gels located at the center of the Aloe vera (harvested from Kimjeonmoon Aloe Farm Co., Jeju, Korea, 2020), and whose parts also included the latex layers of the leaf. Then, $100 \mathrm{~g}$ of freeze-dried outer layers of aloe leaf were extracted with distilled water $(1: 10, w / v)$ at $100{ }^{\circ} \mathrm{C}$ for $24 \mathrm{~h}$ using a vertical reflux condenser (TL-6, Misung Scientific, Yangjoo, Korea). Then, the extracts were centrifuged (Combi 514R; Hanil Science Medical, Daejeon, Korea) at $9000 \times g$ for $30 \mathrm{~min}$ at room temperature, and the supernatants were condensed in a rotary vacuum evaporator (EV-101, Eyela, Tokyo, Japan). Afterward, the concentrates were freeze-dried with a lyophilizer (PVTFA, 10AT, IlShin, Suwon, Korea) to obtain aloe powder (AW) before the experiments. For lactic acid fermentation, $3 \%(v / v)$ of $1 \times 10^{6} \mathrm{CFU} / \mathrm{mL}$ L. plantarum (14917, ATCC, Manassas, VA, USA) was inoculated into $1 \mathrm{~L}$ of distilled water containing 10 $(\%, w / v)$ dried Aloe vera leaf skins and MRS culture medium (Sigma, St. Louis, MO, USA) and grown for 3 days at $37^{\circ} \mathrm{C}$ in a shaking incubator (KB-105, Korea Biotech., Seoul, Korea) at a shaking speed of $100 \mathrm{rpm}$. After cultivation, the culture was further extracted with an ultrasonicator (AUG-R3-900, Asia Ultrasonic, Bucheon, Korea) at a fixed frequency of $40 \mathrm{kHz}$ with $1500 \mathrm{~W}$ of input power for $1 \mathrm{~h}$ at room temperature, and the culture broth was centrifuged at $9000 \times g$ for $30 \mathrm{~min}$ at room temperature. Then, the supernatant was concentrated with a rotary vacuum evaporator and freeze-dried to prepare a powder that 
was designated Aloe vera skin leaf fermented lysates (AF). All extracts were stored at $-20^{\circ} \mathrm{C}$ before use.

\subsection{Measurement of Quercetin Concentrations in the Samples}

The concentrations of quercetin in the 2 samples, AW and AF, were measured using high-performance liquid chromatography (HPLC, E2695, Waters, MA, USA) as follows [24]: $10 \mu \mathrm{L}$ of each sample were injected into an HPLC equipped with an PDA detector (2998, Waters, Milford, MA, USA) and a C18 column $(4.6 \times 150 \mathrm{~mm}, 5 \mu \mathrm{m}$, Luna, Phenomenex, CA, USA). The mobile phase was composed of $0.01 \mathrm{M} \mathrm{KH}_{2} \mathrm{PO}_{4}$ (pH 3.0) (A): methanol (B), and elution was performed using a $0-80 \%$ (B) linear gradient for $30 \mathrm{~min}$ at a $1.0 \mathrm{~mL} / \mathrm{min}$ flow rate. The wavelength of the detector was $280 \mathrm{~nm}$, and $35{ }^{\circ} \mathrm{C}$ of column temperature was used. The concentrations of quercetin in the samples were calculated using a linear regression curve from the peak areas of 10 to $100 \mathrm{ppm}$ of standard quercetin and reported as mg quercetin/g of sample.

\subsection{Measurement of the Cytotoxicity of the Samples}

The cytotoxicity of the samples was determined by using the 3-(4,5-dimethythiazo2-yl)-2,5-diphenyltetrazolium bromide (MTT) assay [25]. For this experiment, $1.0 \times 10^{4}$ human fibroblast cells/well (CCD-986sk, ATCC, Manassas, VA, USA) were inoculated into a 96-well plate and subsequently incubated with DMEM supplemented with 10\% $(v / v)$ fetal bovine serum (FBS) (GIBCO, Bend, OR, USA), 1\% gentamycin sulfate (Sigma, St. Louis, MO, USA), and HEPES buffer (Sigma, St. Louis, MO, USA) in a $5 \% \mathrm{CO}_{2}$ incubator at $37^{\circ} \mathrm{C}$ for $24 \mathrm{~h}$. Then, $200 \mu \mathrm{L}$ of various concentrations of $\mathrm{AW}$ and AF were added into the cells and cultured for $24 \mathrm{~h}$. Then, a $5 \mu \mathrm{g} / \mathrm{mL}$ of MTT solution was added to each well, and the supernatant was removed $4 \mathrm{~h}$ later. Thereafter, $10 \mu \mathrm{L}$ of acid-isopropanol $(0.04 \mathrm{~N} \mathrm{HCl}$ in isopropanol) were added to the wells, and the absorbance of the solution was measured using a microplate reader (Thermo Fisher Scientific, Waltham, MA, USA) at a wavelength of $565 \mathrm{~nm}$. Cytotoxicity was estimated as the percentage of the ratio of cell growth of the treated samples to that of untreated cells as a control using the following Equation (1):

$$
\text { Cytotoxicity }(\%)=\left(1-\frac{\text { Sample group }}{\text { Untreated group }}\right) \times 100
$$

The effects of the samples on preventing the decrease in mitochondrial reductase activities were also observed after human skin fibroblasts (CCD-986sk) were exposed to $\mathrm{UV}_{\mathrm{b}}$ at a wavelength of $312 \mathrm{~nm}$ and intensity of $80 \mathrm{~mJ} / \mathrm{cm}^{2}$ using an ultraviolet lamp (model VL-6 M, Vilber Lourmat, Marine, France) for $120 \mathrm{~s}$ at room temperature. Then, $100 \mu \mathrm{L}$ of various concentrations of $\mathrm{AW}$ and $\mathrm{AF}$ and $10 \mu \mathrm{g} / \mathrm{mL}$ quercetin (Sigma, St. Louis, $\mathrm{MO}, \mathrm{USA}$ ) as a positive control were added into the wells and cultured for $24 \mathrm{~h}$. Afterward, $5 \mu \mathrm{g} / \mathrm{mL}$ of MTT solution was added to each well and analyzed using the same MTT assay protocol as described above for the cytotoxicity assay. The increase in the mitochondrial activities of the samples was calculated using the same Equation (1) shown above.

\subsection{Measurement of the Antioxidant Activities of the Samples}

For the analysis of the antioxidant activities of the samples, 2,2 diphenyl-1picrylhydrazyl (DPPH) free radical scavenging activities and the concentrations of reactive oxygen species (ROS) in the cells were measured. First, DPPH free radical scavenging activities were estimated [26] by adding $80 \mu \mathrm{L}$ of various concentrations of the 2 samples, $\mathrm{AW}$ and AF, $10 \mu \mathrm{g} / \mathrm{mL}$ quercetin or $0.05 \%(w / v)$ Trolox (Sigma, St. Louis, MO, USA) as a positive control to $200 \mu \mathrm{L}$ of $0.1 \mathrm{mM}$ DPPH dissolved in ethanol in a 96-well plate and incubating the mixture at $25{ }^{\circ} \mathrm{C}$ for $20 \mathrm{~min}$ in the dark. Afterward, the absorbance of 
the mixture was measured at $525 \mathrm{~nm}$ using a microplate reader. The DPPH free radical scavenging activity (\%) of the samples was estimated using the following Equation (2):

$$
\text { DPPH radical scavenging activity }(\%)=\left(\frac{\text { Control O.D. }- \text { Sample O.D. }}{\text { Control O.D. }}\right) \times 100
$$

Intracellular ROS production in human fibroblasts was also measured using $2^{\prime}, 7^{\prime}$ dichlorofluorescein diacetate (H2-DCF-DA) as described below [27]: First, CCD-986sk cells were dispensed in a 48-well plate at a density of $4.0 \times 10^{4}$ cells/well, and cultured for $24 \mathrm{~h}$ with DMEM supplemented with $10 \%$ FBS at $37^{\circ} \mathrm{C}$. Thereafter, the culture medium in each well was replaced with a thin layer of phosphate-buffered saline (PBS) (pH 7.4) (Sigma, St. Louis, MO, USA), and the cells were exposed to $\mathrm{UV}_{\mathrm{b}}$ at a wavelength of $312 \mathrm{~nm}$ and an intensity of $80 \mathrm{~mJ} / \mathrm{cm}^{2}$ using an ultraviolet lamp (model VL-6 M, Vilber Lourmat, Marine, France) for $120 \mathrm{~s}$ at room temperature. Then, $100 \mu \mathrm{L}$ of various concentrations of the 2 samples, $\mathrm{AW}$ and $\mathrm{AF}$, and $10 \mu \mathrm{g} / \mathrm{mL}$ quercetin as a positive control were added to the wells and further cultured for $24 \mathrm{~h}$. Subsequently, the cells were washed with PBS and treated with $10 \mu \mathrm{M}$ DCF-DA in Hank's balanced salt solution in a dark room for $30 \mathrm{~min}$. The cells were washed with PBS, suspended in $1 \%$ Triton X-100, and the absorbance was measured using a fluorescence spectrophotometer (UTX-20M, Biostep Co., Burkhardsdorf, Germany) at an excitation wavelength of $490 \mathrm{~nm}$ and an emission wavelength of $525 \mathrm{~nm}$.

\subsection{Estimation of Mitochondrial Activities in $U V_{b}$-Irradiated Human Fibroblasts}

The mitochondrial enzyme activities in human fibroblast cells were observed by measuring the levels of succinate dehydrogenase activity with a mitochondrial complex II activity assay kit (K660, BioVision, Inc., Milpitas, CA, USA) as follows [28]: First, CCD986sk cells exposed to $\mathrm{UV}_{\mathrm{b}}$ using the same protocols for estimating ROS contents. Then, $100 \mu \mathrm{L}$ of various concentrations of the samples and $10 \mu \mathrm{g} / \mathrm{mL}$ quercetin as a positive control were added into the wells and further cultured for $24 \mathrm{~h}$. Then, $2 \mu \mathrm{L}$ of mitochondrial samples were isolated from the cells using a mitochondria isolation kit (K288-50, BioVision, CA, USA) and mixed with a mixture of $15 \mu \mathrm{L}$ of assay buffer, $2 \mu \mathrm{L}$ of antimycin A as an inhibitor and $2 \mu \mathrm{L}$ of DMSO. Next, $6 \mu \mathrm{L}$ of cytochrome c was added as a substrate. Afterward, the absorbance was measured at $550 \mathrm{~nm}$ at $30 \mathrm{~s}$ intervals for up to $10 \mathrm{~min}$ using a microplate reader. The specific activity of mitochondrial complex II was estimated by comparing the absorbance of the sample and the control using Equation (3).

$$
\text { Mitochondrial complex II specific activity }=\Delta \mathrm{C} /(\Delta \mathrm{t} \times \mathrm{p}) \times \mathrm{D}(\text { Units } / \mu \mathrm{g})
$$

where $\Delta \mathrm{C}=$ the change in the reduced cytochrome c concentration during $\Delta \mathrm{t}, \Delta \mathrm{t}=\mathrm{t} 2-\mathrm{t} 1$ $(\mathrm{min}), \mathrm{p}=$ mitochondrial protein sample $(\mu \mathrm{g})$ and $\mathrm{D}=$ dilution factor.

\subsection{Measurement of Collagen Production by $U V_{b}$-Irradiated Human Fibroblasts Treated with the Samples}

The production of collagen by CCD-986sk cells treated with or without $\mathrm{UV}_{\mathrm{b}}$ irradiation was measured using a Procollagen Type 95 I C-peptide (PIP) EIA Kit (Takara, Otsu, Japan) [29]. A total of $100 \mu \mathrm{L}$ of the antibody-POD conjugate solution were added to the plate provided with the kit, and $20 \mu \mathrm{L}$ of different concentrations of each sample was added to the plate in which the $\mathrm{UV}_{\mathrm{b}}$-irradiated or non- $\mathrm{UV}_{\mathrm{b}}$-irradiated cells were cultured with DMEM supplemented with FBS for $24 \mathrm{~h}$. Next, $0.1 \mathrm{ng} / \mathrm{mL}$ transforming growth factor- $\beta 1$ (TGF- $\beta 1$, Sigma, St. Louis, MO, USA) and $10 \mu \mathrm{g} / \mathrm{mL}$ quercetin were added as positive controls. Then, the cells were cultured for $3 \mathrm{~h}$ at $37^{\circ} \mathrm{C}$ in the dark. Afterward, the culture medium was removed, and the cells were washed 3 times with $400 \mu \mathrm{L}$ of washing buffer. After washing, the substrate solutions were added to each well and incubated for $15 \mathrm{~min}$ at room temperature. Then, the reaction was stopped by adding $100 \mu \mathrm{L}$ of $1 \mathrm{~N} \mathrm{H}_{2} \mathrm{SO}_{4}$ to each well and shaking for $1 \mathrm{~min}$. The optical density was measured at $450 \mathrm{~nm}$ with a microplate reader and quantified using the standard curve provided with the kit. 


\subsection{Measurement of the Inhibition of Matrix Metalloproteinase-1 (MMP-1) Synthesis by the Samples}

First, $1.0 \times 10^{5}$ human fibroblasts $/ \mathrm{mL}$ (CCD-986sk) were exposed to $\mathrm{UV}_{\mathrm{b}}$ using the same protocols described for ROS measurements or were not exposed to $\mathrm{UV}_{\mathrm{b}}$ irradiation. Then, after removing a thin layer of PBS from each well, various concentrations of the extracts and $0.1 \%(w / v)$ retinol (trans-retinol, Sigma, St. Louis, MO, USA) and $10 \mu \mathrm{g} / \mathrm{mL}$ quercetin as positive controls in fresh medium were added to the wells and further incubated for $48 \mathrm{~h}$. Afterward, $100 \mu \mathrm{L}$ of the medium were transferred to the plate provided with the human MMP-1 ELISA Kit (RayBiotech, Norcross, GA, USA) and reacted for $2 \mathrm{~h}$ at room temperature. After the reaction, the medium was removed from the wells, cells were washed with PBS washing buffer 4 times, and $100 \mu \mathrm{L}$ of MMP-1 detection antibody were added to each well. Then, the plates were further incubated for $1 \mathrm{~h}$ at room temperature. Next, the medium in the well was removed, cells were washed with PBS again, and $10 \mu \mathrm{L}$ of streptavidin solution was added, followed by shaking for $45 \mathrm{~min}$ at room temperature. The medium in the well was removed again, and cells were washed with PBS buffer two times. Then, $100 \mu \mathrm{L}$ of substrate reagent were added to the well and incubated at room temperature for $30 \mathrm{~min}$ in the dark. Finally, the reaction was stopped by adding $50 \mu \mathrm{L}$ of stop solution. The inhibition of MMP-1 production was measured by comparing the absorbance of the samples in each well at $450 \mathrm{~nm}$ with a linear regression curve of the standard [30].

\subsection{Reverse Transcription Polymerase Chain Reaction (RT-PCR)}

The expression levels of the collagen genes in human fibroblasts with or without $\mathrm{UV}_{\mathrm{b}}$ exposure were measured using RT-PCR [31]. Total RNA was extracted from the cells grown in the presence of the samples after being exposure to $U_{\mathrm{b}}$ or not using TRIzol reagent (Invitrogen Life Technologies, Carlsbad, CA, USA). Then, cDNAs were obtained from $1 \mathrm{mg}$ of RNA using the reverse transcriptase provided with the cDNA kit (First Strand cDNA Synthesis Kit, Fermentas, Hanover, MD, USA) at $37^{\circ} \mathrm{C}$ for $1 \mathrm{~h}$. Afterward, $0.5-2 \mathrm{~mL}$ of cDNA templates and a ReddyMixTM PCR master mix (Abgene, Surrey, UK) were mixed and PCR was performed using a thermocycler (XP Thermal Cycler, TC-XP, BIOER Tech. Co., Hangzhou, China). The optimal conditions for obtaining PCR products of collagen genes were 28 amplification cycles and 30 amplification cycles at $94{ }^{\circ} \mathrm{C}, 1 \mathrm{~min}, 60^{\circ} \mathrm{C}, 1 \mathrm{~min}$ and $72{ }^{\circ} \mathrm{C}, 1 \mathrm{~min}$, respectively. The sequences of the oligonucleotide primers for collagen and GAPDH (a housekeeping gene) were as follows (Biogenia, Seoul, Korea): collagen (forward, 5' -CTC GAG GTG GAC ACC ACC CT-3'; reverse, $5^{\prime}$-CAG CTG GAT GGC CAC ATC GG-3'), and GAPDH (forward, 5' -ATT GTT GCC ATC AAT GAC CC-3'; reverse, $5^{\prime}$ -AGT AGA GGC AGG GAT GAT GT- $3^{\prime}$ ). The PCR products were electrophoresed in $2 \%$ agarose gels and stained with ethidium bromide. Thereafter, the gels were quantified using a densitometry program (Bio ID; Vilber Lourmat, Torcy Z.I., France).

\subsection{Statistical Analysis}

All experiments were repeated 3 times, and the results were presented as the means $\pm \mathrm{SD}$ (standard deviations). Statistical significance was analyzed using one-way analysis of variance (ANOVA) (SAS 9.1, SAS, Cary, NC, USA).

\section{Results and Discussion}

\subsection{Concentrations of Quercetin in the Samples}

Figure 1 was to compare the HPLC chromatograms of quercetin and two samples (AW and $\mathrm{AF}$ ) to estimate the contents of quercetin in the samples. 

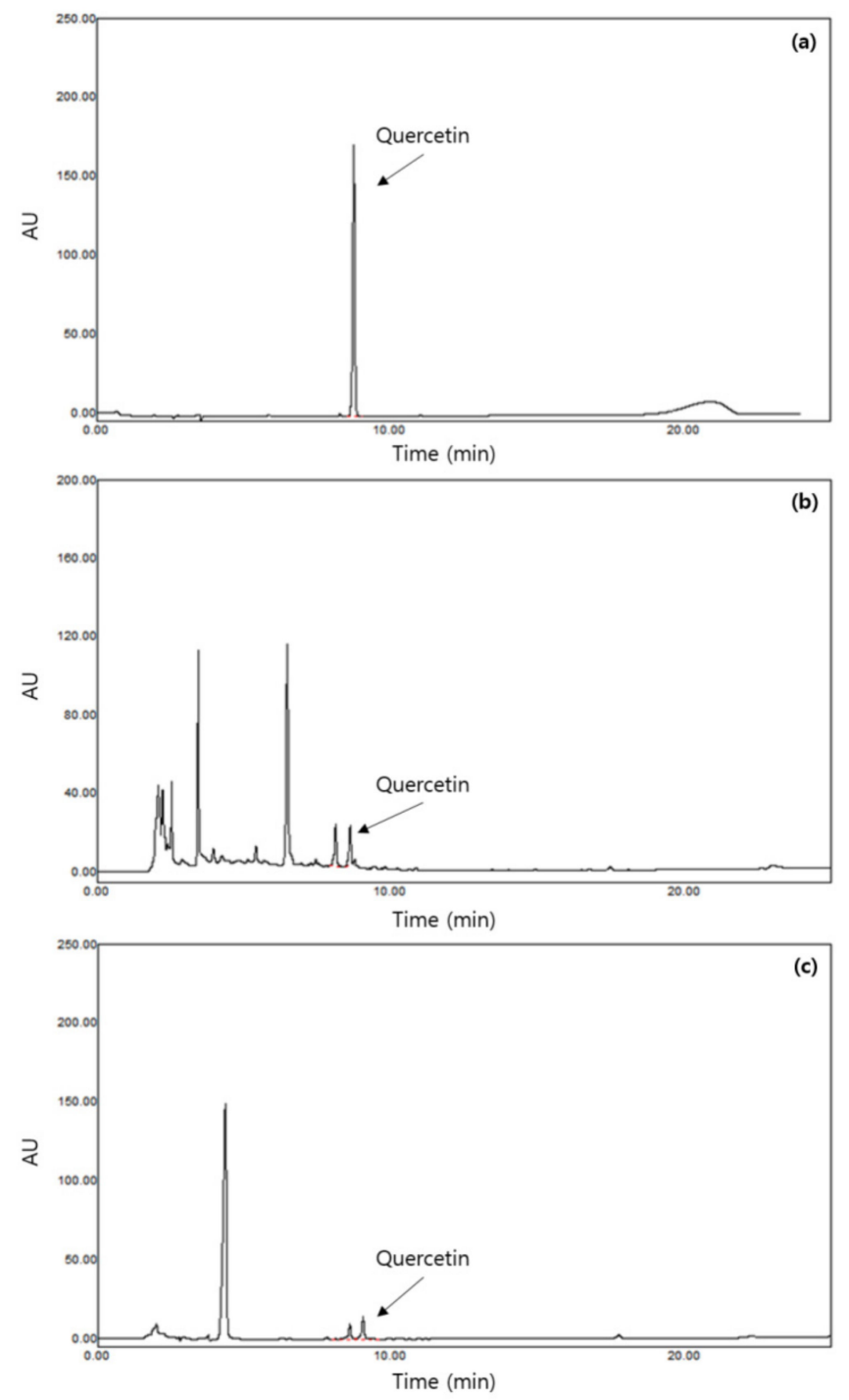

Figure 1. Comparison of HPLC chromatogram of quercetin and two samples: (a) quercetin standard; (b) $\mathrm{AW}$, hot water extraction of outer layers of leaf skin of Aloe vera at $100{ }^{\circ} \mathrm{C}$ for $24 \mathrm{~h}$; (c) AF, L. plantarum fermentation of outer layers of leaf skin of Aloe vera at $37^{\circ} \mathrm{C}$ for 3 days and further extracted by an ultrasonicator at $40 \mathrm{kHz}$ for $1 \mathrm{~h}$ at room temperature.

Table 1 is the result of the linearity test of the standard curves in terms of the correlation coefficient $\left(\mathrm{R}^{2}\right)$ from the integrated peak area of the chromatogram $(\mathrm{Y})$ versus the concentrations of quercetin $(X, \mu \mathrm{g} / \mathrm{mL})(\mathrm{n}=3$, five concentration points). The method was linear between 298.5 and $3825.1 \mu \mathrm{g} / \mathrm{mL}$ for the AW and 273.4 and $3589.2 \mathrm{ug} / \mathrm{mL}$ for the AF. The correlation coefficients were satisfactorily greater than 0.999 , implying that there was strong linear relationship between peak areas and the amounts of quercetin in the sample. 
Table 1. Linearity for quercetin analyzed.

\begin{tabular}{cccccc}
\hline Component & Range $(\boldsymbol{\mu g} / \mathbf{m L})$ & Equation for Regression Line & $\mathbf{R}^{\mathbf{2}}$ & SD Intercept & SD Slope \\
\hline AW & $298.5-3825.1$ & $\mathrm{Y}=1.534 \mathrm{X}+59.0595$ & 0.9997 & 38.35 & 0.19 \\
AF & $273.4-3489.2$ & $\mathrm{Y}=1.207 \mathrm{X}+35.8621$ & 0.9996 & 36.41 & 0.10 \\
\hline
\end{tabular}

$\mathrm{X}$, concentration (ug/mL); $\mathrm{Y}$, peak area; $\mathrm{R}^{2}$; correlation coefficient.

The contents of quercetin in the samples, outer layers of aloe leaf extracts (AW) and the fermented extract (AF) were measured as $3.45 \mathrm{mg} / \mathrm{g}$ and $3.31 \mathrm{mg} / \mathrm{g}$, respectively, and their concentrations were much higher than the value of $0.012 \mathrm{mg} / \mathrm{g}$ detected in the gels from Aloe vera [32], while other studies have also reported similar contents of quercetin in Aloe vera ranging from 0.093 to $10.94 \mathrm{mg} / \mathrm{g}$, depending on the parts examined [33-35]. This result would support the advantage of fermenting the plant resources to have higher elution of bioactive substances [18-20]. In particular, the outer layers of Aloe vera contained much higher amounts of quercetin than the gels that are most often consumed, and a similar result was also reported in another study [36]. In the present study, the amount of quercetin in the AF was not much lower than that in the AW, although the AW was further fermented by lactic acid bacteria to make the AF. Therefore, quercetin was not substantially degraded during the fermentation process once it was extracted from the outer layers of aloe leaf. Moreover, quercetin could work together with other bioactive substances produced by lactic acid bacterial fermentation, which eventually results in greater synergistic effects of AF than AW. Based on this assumption, AF is expected to exhibit good efficacy in terms of the anti-skin aging effects since quercetin has been shown to have high efficacy in treating skin disorders, such as wound healing and wrinkling [37], possibly through synergistic effects of quercetin and other components of the AF.

\subsection{Cytotoxicity and the Prevention of Mitochondrial Dysfunction by the Samples}

As shown in Figure 2, AW and AF were not cytotoxic to human fibroblasts and even increased mitochondrial enzyme activities in a concentration-dependent manner. In general, most plant extracts have shown wide ranges of cytotoxicity, inducing the death of up to $60-70 \%$ of cells in MTT experiments at high dosages. In contrast, in the present study, both the AW and AF improved mitochondrial activities as the treatment concentrations increased to $0.3 \%(w / v)$ and remained relatively constant, similar to a plateau, at higher dosages. Thus, the extracts from Aloe vera leaf skin have the ability to increase the enzymatic activities of mitochondrial dehydrogenase. Specifically, AF substantially increased the mitochondrial enzyme activities of human fibroblasts up to $163.50 \pm 2.21 \%$ of the control, while their activities were increased to ca. $122.31 \pm 3.54 \%$ by AW at a concentration of $0.3 \%$, which also showed a concentration dependence. Upon treatment with concentrations greater than $0.3 \%$, no further increase in enzyme activity was observed but no serious decrease was observed. This result indicates that $\mathrm{AF}$ improves mitochondrial activities and is not cytotoxic, at even higher concentrations. Quercetin in the extracts could play an important role in increasing mitochondrial activities and exerts a synergistic effect with other bioactive substances in the extracts, especially in the AF, compared to the AW. As shown in Figure 2, AW and AF may increase mitochondrial enzyme activities. Therefore, Figure 3 shows whether AF altered the mitochondrial activities of human skin fibroblasts by comparing the succinate-tetrazolium reductase activities of $\mathrm{UV}_{\mathrm{b}}$-irradiated human fibroblasts because $\mathrm{UV}_{\mathrm{b}}$ light is known to be the main factor caused to skin photoaging [5]. A total of $38.10 \pm 2.83 \%$ decrease in mitochondrial reductase activities only in being exposed to $\mathrm{UV}_{\mathrm{b}}$ light was observed compared to the control cells (not exposed to $\mathrm{UV}_{\mathrm{b}}$ ). After treatment with $10 \mu \mathrm{g} / \mathrm{mL}$ quercetin, the activity of this enzyme recovered up to $92.31 \pm 3.45 \%$ of the control level in $\mathrm{UV}_{\mathrm{b}}$-irradiated skin fibroblasts, while the enzyme activities were increased up to $112.57 \pm 5.25 \%$ and $109.30 \pm 1.41 \%$ after the addition of $0.3 \%$ and $0.5 \% \mathrm{AW}$, respectively. 


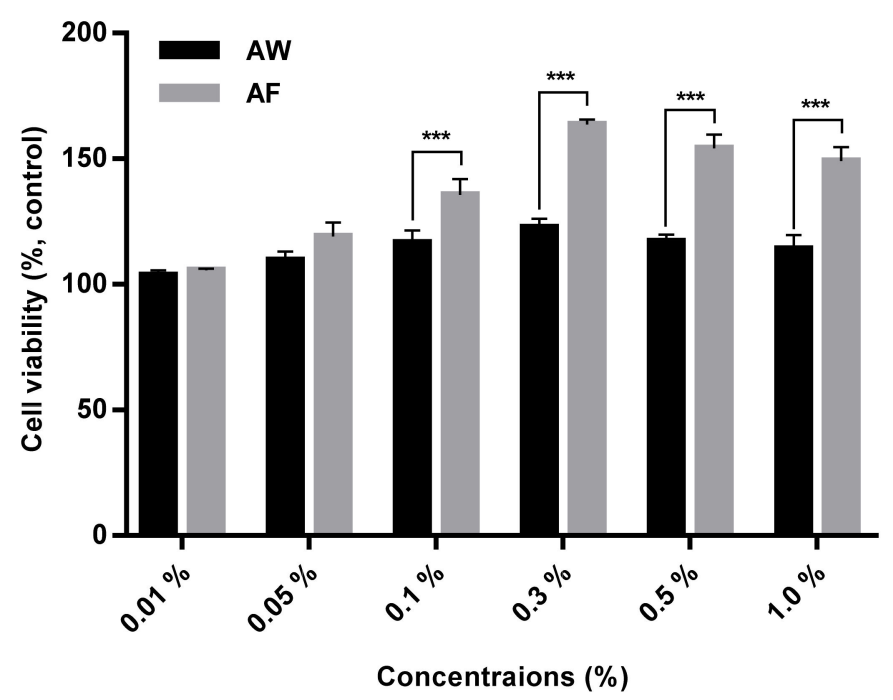

Figure 2. Cytotoxicity of the Aloe vera leaf skin extracts prepared using two different processes against human skin fibroblast cells. AW: Hot water extraction of Aloe vera leaf skin at $100{ }^{\circ} \mathrm{C}$ for $24 \mathrm{~h}$. AF: L. plantarum fermentation of Aloe vera leaf skin at $37^{\circ} \mathrm{C}$ for 3 days and extraction using an ultrasonicator at $40 \mathrm{kHz}$ for $1 \mathrm{~h}$ at room temperature. The mean values $\pm \mathrm{SD}$ for separate triplicate experiments are shown, and error bars represent the SD. The significance of the difference was set to *** $p<0.001$ compared with each group.

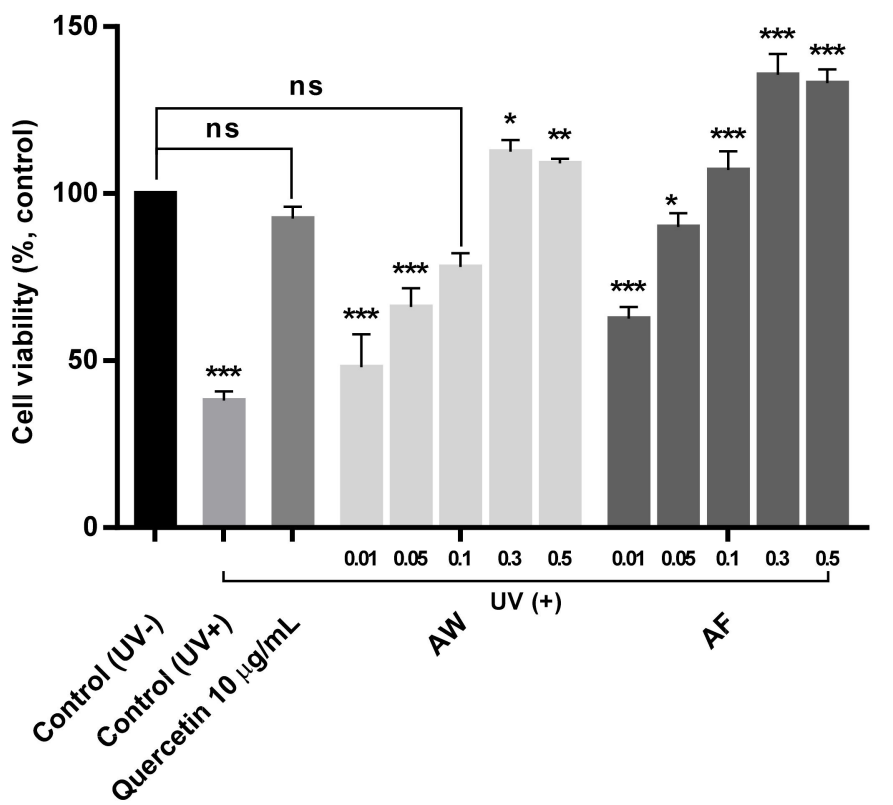

Figure 3. Comparison of mitochondrial reductase activities in $\mathrm{UV}_{\mathrm{b}}$-irradiated human skin fibroblasts treated with $10 \mu \mathrm{g} / \mathrm{mL}$ quercetin and various concentrations of the two aloe extract samples. AW: Hot water extraction of Aloe vera leaf skin at $100{ }^{\circ} \mathrm{C}$ for $24 \mathrm{~h}$. AF: L. plantarum fermentation of Aloe vera leaf skin at $37{ }^{\circ} \mathrm{C}$ for 3 days and extraction with an ultrasonicator at $40 \mathrm{kHz}$ for $1 \mathrm{~h}$ at room temperature. The mean values \pm SD for separate triplicate experiments are shown, and the error bars represent the SD. The significance of the difference was set to ${ }^{*} p<0.05,{ }^{* *} p<0.01$ and ${ }^{* * *} p<0.001$ compared with the control (UV-) group.

These results were also similar to other works that various flavonoids have showed many cytorprotective effects in mitochondrial pathways such as ROS scavenging, ion chelation and antioxidant enzyme transcription, etc. [38-40]. A greater increase was observed in $\mathrm{UV}_{\mathrm{b}}$-irradiated cells treated with $0.3 \%$ of $\mathrm{AF}$, resulting in an increase of up 
to $135.11 \pm 6.36 \%$, but a slight decrease to $133.08 \pm 4.24 \%$ was observed in treating $0.5 \%$ of AF, whose pattern was somewhat different from that of the AW. However, AF shows the ability to protect against mitochondrial damage caused by $U_{\mathrm{b}}$ light, indicating that $\mathrm{AF}$ inhibits the skin aging process by increasing mitochondrial enzyme activities. This interesting effect was speculated to be attributed to the synergistic effects of quercetin and bioactive substances in the AF or AW because a recent study has shown that quercetin plays an important role in increasing mitochondrial activities [41]. In the present study, AF containing the same contents of quercetin also showed higher activities than quercetin itself.

\subsection{DPPH Free Radical Scavenging Effect and the Reduction of ROS Production by the Samples}

First, in Figure 4, antioxidant effects of AF were observed as DPPH free radical scavenging activities and compared with $\mathrm{AW}$ and quercetin, a flavonoid with strong antioxidant effects on human skin cells [42,43], to confirm the hypothesis that AF exerts positive effects on mitochondrial activities that are similar to quercetin. Treatment with $10 \mu \mathrm{g} / \mathrm{mL}$ quercetin, which corresponds to a concentration of $0.3 \%$ of the AF as described in Section 3.1, an ca. $72.56 \pm 3.03 \%$ increase in the free radical scavenging activity was measured compared with the addition of $50 \mu \mathrm{g} / \mathrm{mL}$ Trolox as a positive control, while $74.45 \pm 1.68 \%$ higher antioxidant activity was observed after the addition of $0.3 \%$ of the AW. Compared to antioxidant activities of the AW, a ca. $110.2 \pm 0.71 \%$ higher antioxidant effect was observed after treatment with $0.3 \%$ of AF as the same concentration of the AW that showed the highest efficacy.

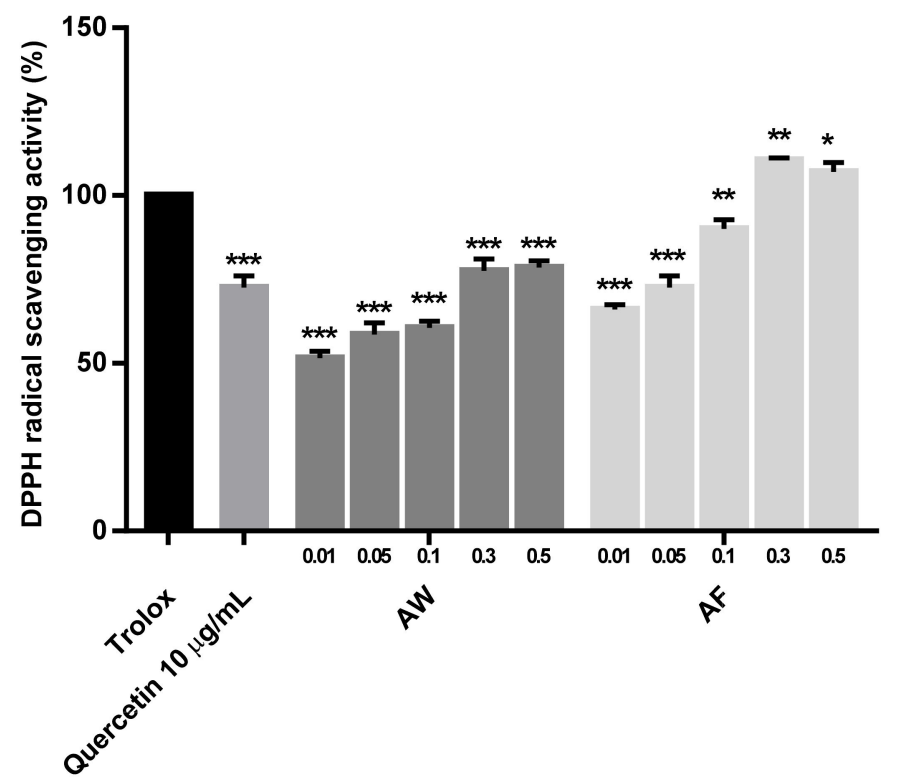

Figure 4. DPPH free radical scavenging activities of various concentrations of two different extracts of Aloe vera leaf skin compared with $10 \mu \mathrm{g} / \mathrm{mL}$ quercetin and $0.05 \%$ Trolox as positive controls. AW: hot water extraction of Aloe vera leaf skin at $100^{\circ} \mathrm{C}$ for $24 \mathrm{~h}$. AF: L. plantarum fermentation of Aloe vera leaf skin at $37{ }^{\circ} \mathrm{C}$ for 3 days and extraction with an ultrasonicator at $40 \mathrm{kHz}$ for $1 \mathrm{~h}$ at room temperature. The mean values \pm SD for separate triplicate experiments are shown, and error bars indicate the SD. The significance of the difference was set to ${ }^{*} p<0.05,{ }^{* *} p<0.01$ and ${ }^{* *} p<0.001$ compared with the Trolox group.

Interestingly, at doses greater than $0.3 \%$, little increase in antioxidant activities was observed for both the AW and AF, and the antioxidant activity even decreased slightly, indicating that an optimum dose might be required for maintaining high antioxidant activities. Moreover, the AF showed higher antioxidant activities, although similar or even lower quercetin contents were present in the AF than in the AW. In the present study, AF, a crude extract, showed higher antioxidant activity than quercetin itself at the same dosage, which strongly implies a synergistic effect of quercetin and other bioactive substances 
in the extracts that were possibly derived from the fermentation of Aloe vera leaf skin by lactic acid bacteria. However, only quercetin itself also exerted various positive effects on human skin cells $[42,44]$. This result indicates the advantages of the fermentation process in employing by-products of aloe processing. In general, ROS generation is presumed to mediate cell death through oxidative stress, such as $U_{\mathrm{b}}$, and subsequently causes mitochondrial dysfunction, which eventually results in the senescence of skin cells [45-47]. Therefore, Figure 5 confirms that the increased antioxidant activity of AF is attributed to the reduced intracellular ROS production from the mitochondria of $\mathrm{UV}_{\mathrm{b}}$-irradiated human skin fibroblasts. More detailed efficacy could be explained by directly measuring mitochondrial ROS generation. The AF substantially inhibited ROS generation compared with the other two samples, the AW and quercetin, at the same dose. As expected, quercetin, a wellknown antioxidant, decreased the intracellular ROS generation down to $82.33 \pm 5.04 \%$ compared to the control (not exposed to $\mathrm{UV}_{\mathrm{b}}$ light), while a $244 \pm 6.33 \%$ increase in ROS production was observed from $\mathrm{UV}_{\mathrm{b}}$-irradiated human skin fibroblasts. After treatment with $0.3 \%$ of the AW, an approximately $80.25 \pm 6.88 \%$ decrease was observed, and an $81.50 \pm 2.12 \%$ decrease was observed after treatment with $0.5 \%$ of the $\mathrm{AW}$, values that were similar to the $82 \%$ observed when adding the same concentration of quercetin itself to the extract. Compared to these results, ROS production was remarkably reduced to $55.40 \pm 4.95 \%$ after treatment with $0.3 \%$ of the $\mathrm{AF}$, and a $53.79 \pm 2.69 \%$ reduction was even observed in the presence of $0.5 \%$ of the AF.

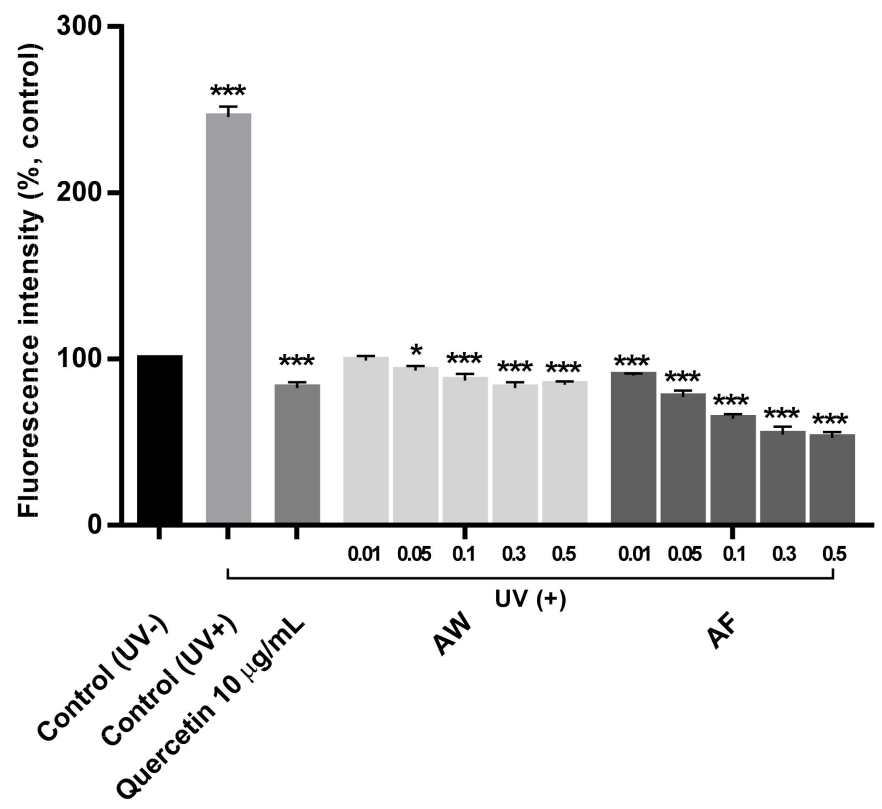

Figure 5. ROS production in $\mathrm{UV}_{\mathrm{b}}$-irradiated human skin fibroblasts treated with $10 \mu \mathrm{g} / \mathrm{mL}$ quercetin and various concentrations of the two aloe extract samples. AW: hot water extraction of Aloe vera leaf skin at $100{ }^{\circ} \mathrm{C}$ for $24 \mathrm{~h}$. AF: L. plantarum fermentation of Aloe vera leaf skin at $37^{\circ} \mathrm{C}$ for 3 days and extraction with an ultrasonicator at $40 \mathrm{kHz}$ for $1 \mathrm{~h}$ at room temperature. The mean values $\pm \mathrm{SD}$ for separate triplicate experiments are shown, and error bars indicate the SD. The significance of the difference was set to ${ }^{*} p<0.05$ and ${ }^{* *} p<0.001$ compared with the control (UV-) group.

These results definitely confirm that the AF protects against oxidative stress in mitochondria because of its strong antioxidant effects that incorporate synergistic effects with quercetin. Moreover, the AF protects against mitochondrial dysfunction induced by $\mathrm{UV}_{\mathrm{b}}$ light, which can inhibit skin aging by reversing mitochondrial dysfunction caused by exogenous stresses. This hypothesis is supported by recent studies showing that quercetin prevents mitochondrial damage induced by several exogenously and endogenously produced cellular stressors and oxidative stress [41]. As shown in Figure 5, quercetin itself and quercetin present in the AW and AF prevented intracellular ROS generation induced by 
$\mathrm{UV}_{\mathrm{b}}$ light. Therefore, as shown in Figure 5, the reduction in ROS production by damaged skin fibroblast cells treated with the AF suggests that the AF mediates the skin antiaging process because quercetin and its derivatives were proven to attenuate the skin healing process [37] effectively. However, a more exact effect of the fermented aloe leaf on mitochondrial protection should be correlated by measuring mitochondrial ROS generations after being exposed with $\mathrm{UV}_{\mathrm{b}}$ light.

\subsection{The Restoration of Mitochondrial Cytochrome II Activities in $U V_{b}$-Irradiated Human Fibroblasts}

Further evidence of the protective effect of AF on mitochondria damaged by $\mathrm{UV}_{\mathrm{b}}$ light is shown in Figure 6, where mitochondrial cytochrome II activities are compared in $\mathrm{UV}_{\mathrm{b}}$-irradiated skin fibroblasts because succinate dehydrogenase (SDH) is an enzyme complex that is bound to the inner mitochondrial membrane in respiratory complex II and is considered to prevent ROS generation $[11,48]$. A more recent study also revealed a strong correlation between age and a significant decrease in complex II activity that was specific to senescent skin cells but not with a decrease in complex IV activity [49]. Therefore, the results of Figure 6 suggest that the ability of the AF to protect against mitochondrial dysfunction due to exogenous stress prevents the skin aging process.

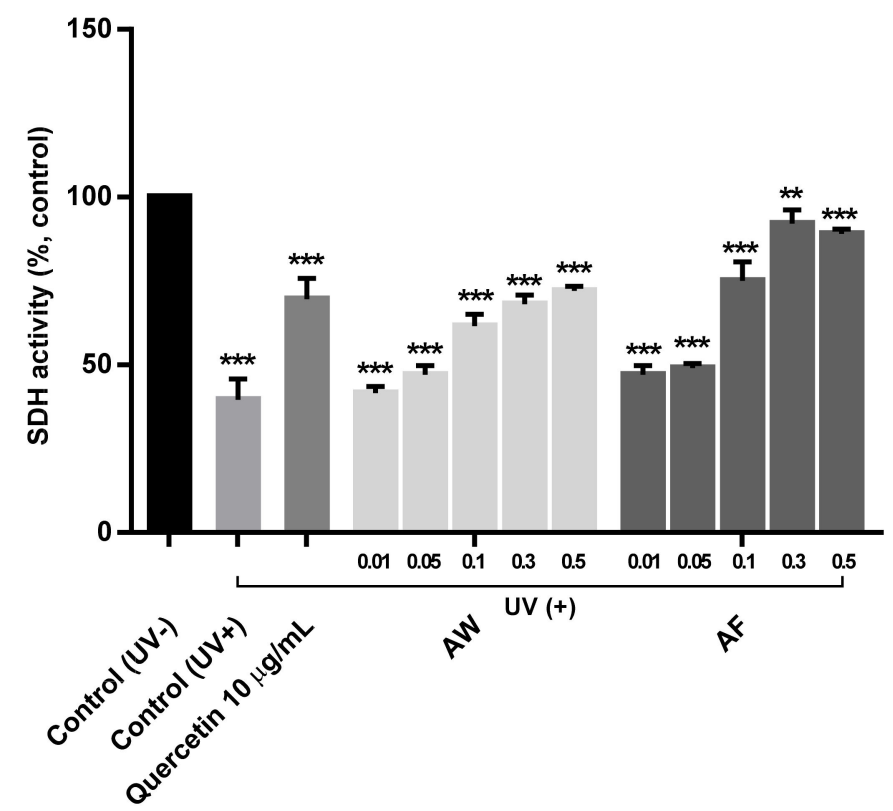

Figure 6. Comparison of succinate dehydrogenase activities, a component of mitochondrial complex II, in $\mathrm{UV}_{\mathrm{b}}$-irradiated human skin fibroblasts treated with $10 \mu \mathrm{g} / \mathrm{mL}$ quercetin or various concentrations of the two aloe extract samples. AW: Hot water extraction of Aloe vera leaf skin at $100{ }^{\circ} \mathrm{C}$ for 24 h. AF: L. plantarum fermentation of Aloe vera leaf skin at $37^{\circ} \mathrm{C}$ for 3 days and extraction with an ultrasonicator at $40 \mathrm{kHz}$ for $1 \mathrm{~h}$ at room temperature. The mean values $\pm \mathrm{SD}$ for separate triplicate experiments are shown, and error bars represent the SD. The significance of the difference was set to ** $p<0.01$ and ${ }^{* * *} p<0.001$ compared with the control (UV-) group.

The protective effect on mitochondria was measured as the ratio of SDH activities in $\mathrm{UV}_{\mathrm{b}}$-irradiated human skin fibroblasts treated with various concentrations of the samples up to $25 \mathrm{mU} / \mathrm{mg}$ to the SDH activities in the control cells (not treated with $\mathrm{UV}_{\mathrm{b}}$ light) (data not shown). In Figure 6, all three samples, quercetin, the AE, and the AF, clearly restored $\mathrm{SDH}$ activity in UVb-irradiated skin cells up to $89.30 \pm 1.14 \%$ of the control after treatment with $0.5 \%$ of the $\mathrm{AF}$, the highest concentration, and similar results were obtained from cells treated with $0.3 \%$ of the AF. Specifically, $10 \mu \mathrm{g} / \mathrm{mL}$ quercetin maintained SDH activity at $69.55 \pm 6.33 \%$ in the mitochondria of UVb-irradiated human fibroblasts, while SDH activities were substantially reduced to $39.06 \pm 3.68 \%$ in cells that were only exposed to 
$\mathrm{UVb}$ light without treatment with the samples. This result was also supported by the recent work that flavonoids have their cytoprotective effects on mitochondrial pathways [10]; especially, quercetin showed the inhibition of oxidative stress by directly scavenging ROS [50]. However, in cells treated with $0.3 \% \mathrm{AW}$ and the AF, SDH enzyme activities were not substantially reduced, and the values were only $68.15 \pm 2.88 \%$ and $92.30 \pm 4.61 \%$ of the control, respectively. Interestingly, a less than $20 \%$ decrease in SDH activity was observed in adding $0.3 \%$ of the $\mathrm{AF}$, which were much better than those obtained with quercetin and AW. These results clearly proved that AF exerts a fairly strong effect on protecting against mitochondrial damage by restoring complex II activity in mitochondrial electron transport pathways since SDH is a key enzyme in the respiratory complex of mitochondria [44]. Therefore, the results of Figures 3, 5 and 6 imply that AF delays/inhibits the skin aging process because complex II was most closely correlated with skin cell aging [49]. However, a more detailed correlation with the activation of mitochondrial function should be explained by considering multi-functional mitochondrial protein such as voltage-dependent anion channel (VDAC) after treating the samples [10].

\subsection{Skin Antiaging Effects of the Samples on $U V_{b}$-Irradiated Human Fibroblasts}

As the results shown in Figure 6, proved that AF protected against mitochondrial dysfunction, further experiments are needed to confirm whether the increase in mitochondrial activities induced by AF affects the antiaging process of human skin. With increasing age, a sustained reduction in collagen levels and increased secretion of matrix-degrading enzymes such as matrix metalloproteinases (MMPs) in old skin were observed compared with young skin $[45,51]$.

Therefore, Figures 7 and 8 show the inhibition of MMP-1 and the production of collagen along with the regulation of gene expression in $U_{V_{b}}$-irradiated human skin fibroblasts. The production of MMP-1, which is also an indicator of skin wrinkling processes, was observed to more clearly prove that the AF is involved in the skin antiaging process, as shown in Figure 7. In Figure 7, after irradiation with $U_{\mathrm{b}}$ light, MMP-1 levels were substantially increased up to $143 \%$ of the control cells (not exposed to $U V_{b}$ light) in which $125 \mathrm{ng} / \mathrm{mL}$ MMP-1 was produced (data not shown), while MMP-1 levels were decreased to $70.57 \pm 3.49 \%$ in $\mathrm{UV}_{\mathrm{b}}$-irradiated cells with $10 \mu \mathrm{g} / \mathrm{mL}$ quercetin. Treatments with $0.3 \%$ and $0.5 \%$ of the AW also resulted in a 75\% reduction in MMP-1 production. Compared to those results, the AF significantly reduced MMP-1 production down to $69.41 \pm 2.63 \%$ at a dose of $0.3 \%$ without a further decrease in the presence of $0.5 \%$ of the AF. As shown in Figure 8a, skin fibroblast cells with mitochondrial damage induced by $\mathrm{UV}_{\mathrm{b}}$ light exhibited significantly reduced collagen production down to $45 \%$ of the $45 \mathrm{ng} / \mathrm{mL}$ collagen produced by the control cells (data not shown). Quercetin alone enhanced the restoration of collagen production, up to $112.37 \pm 8.01 \%$ of the control, after treatment with $10 \mu \mathrm{g} / \mathrm{mL}$ quercetin, and the addition of $0.3 \%$ of the AW induced a restoration effect similar to that of quercetin itself. Moreover, a $125 \pm 5.45 \%$ increase in collagen production was measured after treatment with $0.3 \%$ of the AF. Compared to the control, a value was much higher than that induced by quercetin itself with the same contents in the AF. This result clearly implies a synergistic effect of quercetin and other biological components in the AF. A similar restoration of collagen production was also observed in cells treated with $0.3 \%$ and $0.5 \%$ of the AW and AF. Thus, a saturation concentration may exist after which the extracts are no longer more effective at certain dosages, which in this case was $0.5 \%$. However, the AF has the ability to prevent skin wrinkling processes, specifically in skin photo-aging, possibly by reversing mitochondrial dysfunction. The expression levels of the genes related to collagen production are also shown in Figure 8b,c. As shown in Figure 8b, the expression of collagen genes was substantially upregulated in $\mathrm{UV}_{\mathrm{b}}$-irradiated cells treated with $0.3 \%$ of the AF as the concentration dependency manner (ColA1). Its band intensity was also digitized in Figure 8c for easy comparison with other bands, showing that all of the results were similar patterns to those presented in Figure 8b. Overall speaking, the protective effects of the AF on skin wrinkling appear to be similar to or even better than those of other 
plant extracts, such as Emblica officinalis or alpha-naphthoflavone, etc. [52,53]. However, these reports did not show and/or correlate changes in the production of collagen and the inhibition of MMP-1 with the effects on reversing mitochondrial dysfunction. Compared to those reports, the results of the present study clearly showed that the AF increased collagen production by restoring mitochondrial activities, although the mitochondria of human skin fibroblast cells were damaged by $\mathrm{UV}_{\mathrm{b}}$ light. Therefore, these results indicate that the AF must play an important role in preventing the skin aging process by effectively increasing collagen production and inhibiting MMP-1 production in the presence of exogenous aging factors, such as $U_{\mathrm{b}}$ light. The efficacy of AF was better than that of AW and even much better than quercetin itself, implying that the effects of AF are due to the synergistic effects of quercetin and other bioactive substances produced during lactic acid bacterial fermentation. The results of this study were also supported by other reports showing that plant phenolic compounds possess significant potential to inhibit or even reverse signs of aging, such as wrinkles or hyperpigmentation marks [54].

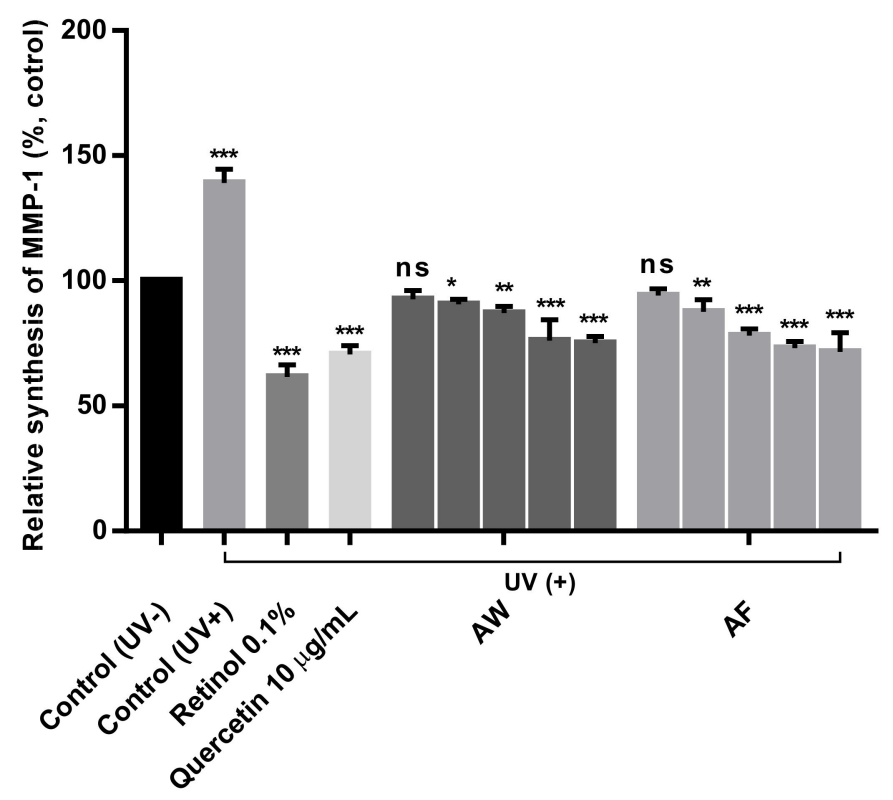

Figure 7. The inhibition of MMP-1 synthesis in $\mathrm{UV}_{\mathrm{b}}$-irradiated human skin fibroblasts treated with $10 \mu \mathrm{g} / \mathrm{mL}$ quercetin and various concentrations of the two different extracts. AW: hot water extraction of Aloe vera leaf skin at $100^{\circ} \mathrm{C}$ for $24 \mathrm{~h}$. AF: L. plantarum fermentation of Aloe vera leaf skin at $37^{\circ} \mathrm{C}$ for 3 days and extraction with an ultrasonicator at $40 \mathrm{kHz}$ for $1 \mathrm{~h}$ at room temperature. The mean values \pm SD for separate triplicate experiments are shown, and error bars indicate the SD. The significance of the difference was set to ${ }^{*} p<0.05,{ }^{* *} p<0.01$ and ${ }^{* * *} p<0.001$ compared with the control group. 
(a)

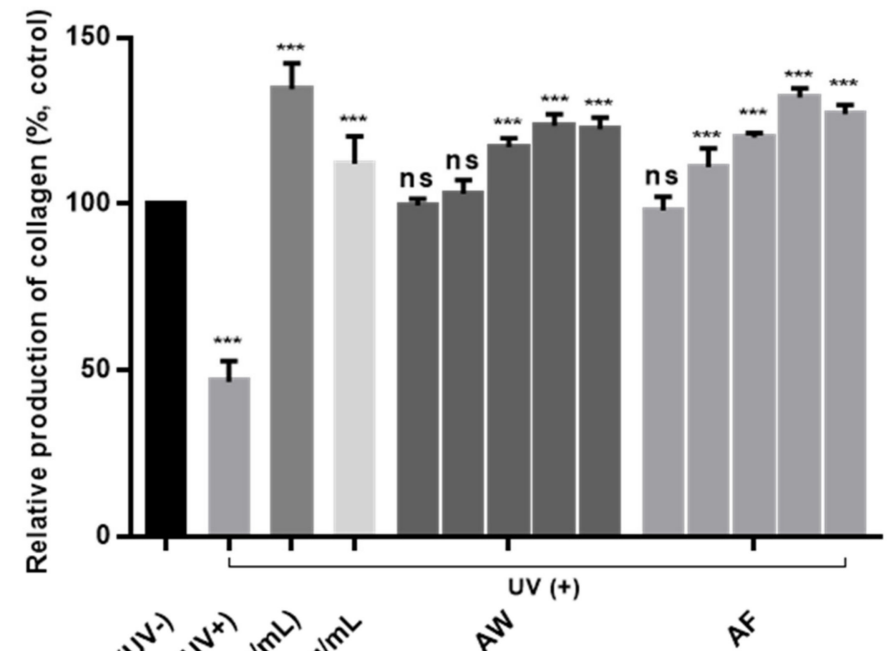

(b)

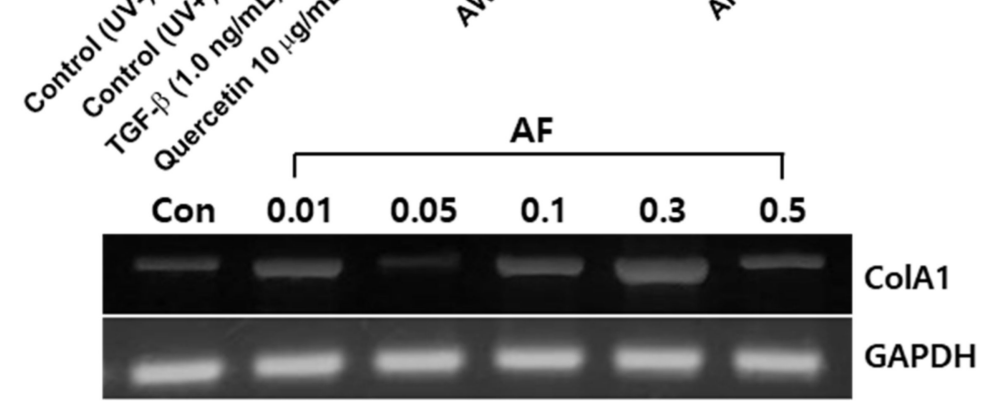

(c)

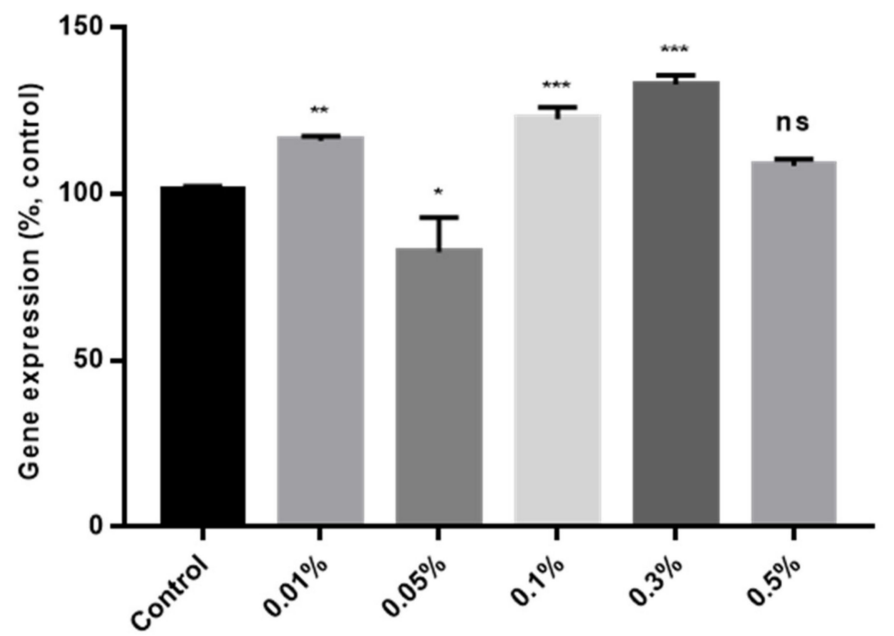

Figure 8. Collagen levels in $\mathrm{UV}_{\mathrm{b}}$-irradiated human skin fibroblasts treated with $10 \mu \mathrm{g} / \mathrm{mL}$ quercetin and various concentrations of the two different extracts (a) along with the densitometric intensities (c) corresponding to each PCR band (b). AW: hot water extraction of Aloe vera leaf skin at $100{ }^{\circ} \mathrm{C}$ for 24 h. AF: L. plantarum fermentation of Aloe vera leaf skin at $37^{\circ} \mathrm{C}$ for 3 days and extraction with an ultrasonicator at $40 \mathrm{kHz}$ for $1 \mathrm{~h}$ at room temperature. The mean values $\pm \mathrm{SD}$ for separate triplicate experiments are shown, and error bars indicate the SD. The significance of the difference was set to ${ }^{*} p<0.05,{ }^{* *} p<0.01$ and ${ }^{* * *} p<0.001$ compared with the control group.

\section{Conclusions}

This study was the first to show that the skin antiaging effects of the Aloe vera leaf skin are significantly increased through the lactic acid bacterial fermentation process, and its increase is closely associated with the restoration of the mitochondrial functions of $\mathrm{UV}_{\mathrm{b}}$-irradiated human skin fibroblasts. Quercetin, an antioxidant flavonoid that exists in the outer layers of aloe leaf, was found to have a cytoprotective effect on mitochondrial pathways by inhibiting oxidative stress. The fermented outer layers of aloe leaf extract (AF) contains similar amounts of quercetin to the AW; however, the AF results in the greatest 
increase in mitochondrial functions, such as mitochondrial enzyme activities and complex II electron transport systems, compared with the hot water extracts of outer layers of aloe leaf $(A W)$ and even quercetin itself. This result strongly implied that higher efficacy of the $\mathrm{AF}$ is attributed to a synergistic effect of quercetin and other bioactive substances from the lactic acid bacterial fermentation process. Specifically, the AF substantially improved the recovery of mitochondrial reductase activities up to $55.40 \pm 4.95 \%$ after treatment with a concentration of $0.3 \%$ by effectively scavenging cellular ROS generated from the oxidative stress of mitochondria, which is closely associated with antioxidant activities of the AF. Additionally, increases in mitochondrial activities induced by the AF result in the inhibition of skin wrinkling processes by increasing collagen production and decreasing MMP-1 production, as well as the expression of the genes encoding these proteins, compared to AW and quercetin itself. Therefore, these results conclude that the restoration of mitochondrial activities damaged by $\mathrm{UV}_{\mathrm{b}}$ light attenuates the acceleration of aging processes of $\mathrm{UV}_{\mathrm{b}}$ irradiated skin fibroblasts. The results of this study could also be applied to develop high-value cosmeceuticals utilizing byproducts from aloe processing.

Author Contributions: Conceptualization, and methodology, H.L. (Hyeonwoo Lee), G.K., H.L. (Hyeonyong Lee); formal analysis, data curation, H.L. (Hyeonwoo Lee), W.C., G.K.; writing-original draft preparation, H.L. (Hyeonyong Lee); writing-review and editing, G.K., H.R., H.L. (Hyeonyong Lee); supervision, project investigation, H.R., H.L. (Hyeonyong Lee). All authors have read and agreed to the published version of the manuscript.

Funding: This research received no external funding.

Institutional Review Board Statement: Not applicable.

Informed Consent Statement: Not applicable.

Data Availability Statement: Generated during the study.

Conflicts of Interest: The authors declare no conflict of interest.

\section{References}

1. Moon, H.J.; Lee, S.R.; Shim, S.N.; Jeong, S.H.; Stonik, V.A.; Rasskazov, V.A.; Zvyagintseva, T.; Lee, Y.H. Fucoidan inhibits UVB-induced MMP-1 expression in human skin fibroblasts. Biol. Pharm. Bull. 2008, 31, 284-289. [CrossRef]

2. Mohamed, M.A.; Jung, M.; Lee, S.M.; Lee, T.H.; Kim, J. Protective effect of Disporum sessile D.Don extract against UVB-induced photoaging via suppressing MMP-1 expression and collagen degradation in human skin cells. J. Photochem. Photobiol. B Biol. 2014, 133, 73-79. [CrossRef]

3. Jenkins, G. Molecular mechanisms of skin ageing. Mech. Ageing Dev. 2002, 123, 801-810. [CrossRef]

4. Agnieszka, G.; Pedro, D.; Elżbieta, S. Proteins involved in the antioxidant and inflammatory response in rutin-treated human skin fibroblasts exposed to UVA or UVB irradiation. J. Dermatol. Sci. 2018, 90, 241-252. [CrossRef]

5. Piao, M.J.; Kim, K.C.; Zheng, J.; Yao, C.W.; Cha, J.W.; Boo, S.J. The ethyl acetate fraction of Sargassum muticum attenuates ultraviolet $\mathrm{B}$ radiation-induced apoptotic cell death via regulation of MAPK- and caspase-dependent signaling pathways in human HaCaT keratinocytes. Pharm. Biol. 2014, 52, 1110-1118. [CrossRef] [PubMed]

6. Choi, S.H.; Choi, S.I.; Jung, T.D.; Cho, B.Y.; Lee, J.H.; Kim, S.H.; Yoon, S.A.; Ham, Y.M.; Yoon, W.J.; Cho, J.H.; et al. Anti-Photoaging Effect of Jeju Putgyul (Unripe Citrus) Extracts on Human Dermal Fibroblasts and Ultraviolet B-induced Hairless Mouse Skin. Int. J. Mol. Sci. 2017, 18, 2052. [CrossRef] [PubMed]

7. Cadet, J.; Davies, K.J.A.; Medeiros, M.H.G.; Mascio, P.D.; Wagner, J.R. Formation and repair of oxidatively generated damage in cellular DNA. Free Radic. Biol. Med. 2017, 107, 13-34. [CrossRef] [PubMed]

8. Yusoff, A.A.M.; Khair, S.Z.N.M.; Radzak, S.M.A.; Idris, Z.; Lee, H.C. Prevalence of mitochondrial DNA common deletion in patients with gliomas and meningiomas: A first report from a Malaysian study group. J. Chin. Med. Assoc. 2020, 83, 838-844. [CrossRef] [PubMed]

9. Balaban, R.S.; Nemoto, S.; Finkel, T. Mitochondria, oxidants, and aging. Cell 2005, 25, 483-495. [CrossRef]

10. Kicinska, A.; Jarmuszkiewicz, W. Flavonoids and mitochondria: Activation of cytoprotective pathways? Molecules 2020, 25, 3060. [CrossRef] [PubMed]

11. Ratree, M.; Nathorn, C.; Surachet, N.; Chuenjid, K. The efficacy of Aloe vera used for burn wound healing: A systematic review. Burns 2007, 33, 713-718. [CrossRef]

12. Supreet, J.; Nirav, R.; Ravleen, N.; Jaideep, S.; Afshan, L.; Naveen, G.; Priyanka, A.; Swati, P. Antibacterial effect of Aloe vera gel against oral pathogens: An in-vitro study. J. Clin. Diagn. Res. 2016, 10, 41-44. [CrossRef] 
13. Langmead, L.; Makins, R.J.; Rampton, D.S. Anti-inflammatory effect of Aloe vera gel in human colorectal mucosa in vitro. Aliment. Pharmacol. Ther. 2004, 19, 521-527. [CrossRef] [PubMed]

14. Chandegara, V.K.; Varshney, A.K. Aloe vera L. processing and products: A review. Int. J. Med. Aromat. Plants 2013, 3, $492-506$.

15. Chang, X.L.; Chen, B.Y.; Feng, Y.M. Water-soluble polysaccharides isolated from skin juice, gel juice and flower of Aloe vera miller. J. Taiwan Inst. Chem. Eng. 2011, 42, 197-203. [CrossRef]

16. Minjares-Fuentes, R.; Femenia, A.; Comas-Serra, F.; Rodríguez-González, V.M. Compositional and structural features of the main bioactive polysaccharides present in the Aloe vera plant. J. AOAC Int. 2018, 101, 1711-1719. [CrossRef] [PubMed]

17. Hidehiko, B.; Kan, S.; Takeshi, C.; Takaaki, K.; Ikuko, T.; Sachiyo, Y.; Sayaka, O.; Hiroshi, K.; Shigeru, S. Antidiabetic effects of dietary administration of Aloe arborescens Miller components on multiple low-dose streptozotocin-induced diabetes in mice: Investigation on hypoglycemic action and systemic absorption dynamics of aloe components. J. Ethnopharmacol. 2006, 103, 468-477. [CrossRef]

18. Kong, B.M.; Park, B.M.; Min, M.J.; Kim, S.Y.; Yang, D.C. Physico-chemicial characteristics of white, fermented and red ginseng extracts. J. Ginseng Res. 2008, 32, 238-243. [CrossRef]

19. Perdigón, G.; Fuller, R.; Raya, R. Lactic acid bacteria and their effect on the immune system. Curr. Issues Intest. Microbiol. 2001, 12, 27-42.

20. Yang, M.C.; Jeong, S.W.; Ma, J.Y. Analysis of constituents in Sipjundaebo-tangs fermented by lactic acid bacteria. Microbiol. Biotechnol. Lett. 2011, 39, 350-358.

21. Lee, H.Y. Improvement of skin barrier dysfunction by Scutellaria baicalensis GEOGI extracts through lactic acid fermentation. J. Cosmet. Dermatol. 2019, 18, 183-191. [CrossRef]

22. Kim, Y.S.; Lee, D.E.; Park, S.D.; Kim, Y.T.; Jeong, J.W.; Chung, D.K.; Lee, J.H. Oral administration of Lactobacillus plantarum HY7714 protects hairless mouse against ultraviolet B-induced photoaging. J. Microbiol. Biotechnol. 2014, 24, 1583-1591. [CrossRef]

23. Lee, X.M.; Lee, H.A.; Kwon, M.; Park, E.S.; Park, K.Y. Probiotic Effects of Lactobacillus plantarum strains isolated from Kimchi. J. Korean Soc. Food Sci. Nutr. 2016, 45, 1717-1724. [CrossRef]

24. Hu, Z.; Wang, X.; Yang, L.; Tan, X.; Bao, T. Determination of quercetin in Yi Gan Qing capsule by HPLC. J. Anhui Agric. Sci. 2008, 36, 9347-9348.

25. Park, H.J.; Cho, J.H.; Hong, S.H.; Kim, D.H.; Jung, H.Y.; Kang, I.K.; Cho, Y.J. Whitening and anti-wrinkle activities of ferulic acid isolated from Tetragonia tetragonioides in B16F10 melanoma and CCD-986sk fibroblast cells. J. Nat. Med. 2018, 72, 127-135. [CrossRef] [PubMed]

26. Frezzini, M.A.; Castellani, F.; Francesco, N.; Ristorini, M.; Canepari, S. Application of DPPH assay for assessment of particulate matter reducing properties. Atmosphere 2019, 10, 816. [CrossRef]

27. Kobashigawa, L.C.; Xu, Y.C.; Padbury, J.F.; Tseng, Y.T.; Yano, N. Metformin protects cardiomyocyte from doxorubicin induced cytotoxicity through an AMP-activated protein kinase dependent signaling pathway: An in vitro study. PLoS ONE 2014, 15, e104888-e104899. [CrossRef]

28. Guo, M.; Wang, X.; Zhao, Y.; Yang, Q.; Ding, H.; Dong, Q.; Chen, X.; Cui, M. Ketogenic diet improves brain ischemic tolerance and inhibits NLRP3 inflammasome activation by preventing Drp1-mediated mitochondrial fission and endoplasmic reticulum stress. Front. Mol. Neurosci. 2018, 20, 29662437-29662452. [CrossRef]

29. Kim, T.Y.; Lee, K.H. Effects of Draconis resina on the collagenase activities and the procollagen synthesis in Hs68 human fibroblasts, and tyrosinase activity. Korea J. Herbol. 2015, 6, 1-6. [CrossRef]

30. Lee, K.E.; Bharadwaj, S.; Yadava, U.; Kang, S.G. Computational and in vitro investigation of (-)-Epicatechin and Proanthocyanidin B2 as inhibitors of human matrix metalloproteinase 1. Biomolecules 2020, 10, 1379. [CrossRef]

31. Chen, B.; Li, Y.; Yan, N.; Chen, G.; Qian, W.; Jiang, H.L.; Ji, C.; Bi, Z.G. Astragaloside IV controls collagen reduction in photoaging skin by improving transforming growth factor- $\beta /$ Smad signaling suppression and inhibiting matrix metalloproteinase-1. Mol. Med. Rep. 2015, 11, 3344-3348. [CrossRef]

32. Sultana, B.; Anwar, F. Flavonols (kaempeferol, quercetin, myricetin) contents of selected fruits, vegetables and medicinal plants. Food Chem. 2008, 108, 879-884. [CrossRef]

33. Silva, A.M.; Trevisan, G.; ZeniKlafke, J.; Rossato, M.F.; Isabel, C.; Walker, B.; Oliveira, S.M.; Silva, C.R.; Boligon, A.; Flores, F.C.; et al. Antinociceptive and anti-inflammatory effects of Aloe saponaria Haw on thermal injury in rats. J. Ethnopharmacol. 2013, 146, 393-401. [CrossRef] [PubMed]

34. Lai, Q.; Wang, H.; Guo, X.; Abbasi, A.M.; Wang, T.; Li, T.; Fu, X.; Li, J.; Liu, R.H. Comparison of phytochemical profiles, antioxidant and cellular antioxidant activities of seven cultivars of Aloe. Int. J. Food Sci. Technol. 2016, 51, 1489-1494. [CrossRef]

35. López, A.; De Tangil, M.S.; Vega-Orellana, O.; Ramírez, A.S.; Rico, M. Phenolic constituents, antioxidant and preliminary antimycoplasmic activities of leaf skin and flowers of Aloe vera (L.) Burm. f. (syn. A. barbadensis Mill.) from the canary islands (Spain). Molecules 2013, 18, 4942. [CrossRef] [PubMed]

36. Nuttila, A.M.; Puupponen-Pimia, R.; Aarni, M.; Oksman-Caldentey, K.M. Comparison of antioxidant activities of onion and garlic extracts by inhibition of lipid peroxidation and radical scavenging activity. Food Chem. 2003, 81, 485-493. [CrossRef]

37. Polerà, N.; Badolato, M.; Perri, F.; Carullo, G.; Aiello, F. Quercetin and its natural sources in wound healing management. Curr. Med. Chem. 2019, 26, 5825-5848. [CrossRef]

38. Shah, Z.A.; Li, R.; Ahmad, A.S.; Kensler, T.W.; Yamamoto, M.; Biswal, S.; Doré, S. The flavanol (-)-epicatechin prevents stroke damage through the Nrf2/HO1 pathway. J. Cereb. Blood Flow Metab. 2010, 30, 1951-1961. [CrossRef] 
39. Perez, C.A.; Wei, Y.; Guo, M. Iron-binding and anti-Fenton properties of baicalein and baicalin. J. Inorg. Biochem. 2009, 103, 326-332. [CrossRef]

40. Arredondo, F.; Echeverry, C.; Abin-Carriquiry, J.; Blasina, F.; Antúnez, K.; Jones, D.; Go, Y.; Liang, Y.; Dajas, F. After cellular internalization, quercetin causes Nrf2 nuclear translocation, increases glutathione levels, and prevents neuronal death against an oxidative insult. Free Radic. Biol. Med. 2010, 49, 738-747. [CrossRef] [PubMed]

41. Oliveira, M.R.; Nabavi, S.M.; Braidy, N.; Setzer, W.N.; Seyed, T.A.; Nabavi, F. Quercetin and the mitochondria: A mechanistic view. Biotechnol. Adv. 2016, 34, 532-549. [CrossRef]

42. Hong, M.S.; Yoon, Y.M.; An, S.K.; An, I.S.; Byun, B.H. Protective effects of the natural ingredient quercetin in human dermal fibroblasts. Asian J. Beauty Cosmetol. 2012, 10, 571-579.

43. Muthukumaran, P.; Divya, R.; Indhumathi, E.; Keerthika, C. Total phenolic and flavonoid content of membrane processed Aloe vera extract: A comparative study. Int. Food Res. J. 2018, 25, 1450-1456.

44. Kim, S.H.; Nam, G.W.; Gang, B.Y.; Lee, H.K.; Moon, S.J.; Chang, I.S. The effect of kaempferol and quercetin on hyaluronansynthesis in human keratinocytes (HaCaT). J. Soc. Cosmet. Sci. Korea 2005, 37, 97-102.

45. Li, Y.F.; Ouyang, S.H.; Tu, L.F.; Wang, X.; Yuan, W.L.; Wang, G.E.; Wu, Y.P.; Duan, W.J.; Yu, H.M.; Fang, Z.Z.; et al. Caffeine protects skin from oxidative stress-induced senescence through the activation of autophagy. Theranostics 2018, 8, 5713-5730. [CrossRef] [PubMed]

46. Phull, A.R.; Nasir, B.; Haq, I.; Kim, S.J. Oxidative stress, consequences and ROS mediated cellular signaling in rheumatoid arthritis. Chem. Biol. 2018, 281, 121-136. [CrossRef] [PubMed]

47. Kaarniranta, K.; Pawlowska, E.; Szczepanska, J.; Jablkowska, A.; Blasiak, J. Role of mitochondrial DNA damage in ROS-mediated pathogenesis of age-related macular degeneration (AMD). Int. J. Mol. Sci. 2019, 20, 2374. [CrossRef]

48. Vera, A.V. Production of reactive oxygen species in brain mitochondria: Contribution by electron transport chain and non-electron transport chain sources. Antioxid. Redox Signal 2005, 7, 1140-1149. [CrossRef]

49. Bowman, A.; Birch-Machin, M.A. Age-dependent decrease of mitochondrial complex II activity in human skin fibroblasts. J. Investig. Dermatol. 2016, 136, 912-919. [CrossRef]

50. Dudylina, A.; Ivanova, M.; Shumaev, K.; Ruuge, E. Superoxide formation in cardiac mitochondria and effect of phenolic antioxidants. Cell Biochem. Biophys. 2019, 77, 99-107. [CrossRef]

51. Varani, J.; Warner, R.L.; Gharaee-Kermani, M.; Phan, S.H.; Kang, S.; Chung, J.H.; Wang, Z.Q.; Datta, S.C.; Fisher, G.j.; Voorhees, J.J. Vitamin A antagonizes decreased cell growth and elevated collagen-degrading matrix metalloproteinases and stimulates collagen accumulation in naturally aged human skin. J. Investig. Dermatol. 2000, 114, 480-486. [CrossRef]

52. Liao, P.L.; Li, C.H.; Chang, C.Y.; Lu, S.R.; Lin, C.H.; Tse, L.S.; Cheng, Y.W. Anti-ageing effects of alpha-naphthoflavone on normal and UVB-irradiated human skin fibroblasts. Exp. Dermatol. 2012, 21, 535-561. [CrossRef] [PubMed]

53. Adil, M.D.; Kaiser, P.; Satti, N.K.; Zargar, A.M.; Vishwakarma, R.A.; Tasduq, S.A. Effect of Emblica officinalis (fruit) against UVB-induced photo-aging in humanskin fibroblasts. J. Ethnopharmacol. 2010, 132, 109-114. [CrossRef] [PubMed]

54. Wittenauer, J.; Mackle, S.; Sussmann, D.; Schweiggert-Weisz, U.; Carle, R. Inhibitory effects of polyphenols from grape pomace extract on collagenase and elastase activity. Fitoterapia 2015, 101, 179-187. [CrossRef] [PubMed] 